\title{
Expression of fibroblast growth factors and their receptors during full-thickness skin wound healing in young and aged mice
}

\author{
Akiko Komi-Kuramochi ${ }^{1}$, Mitsuko Kawano ${ }^{1,2}$, Yuko Oda ${ }^{1}$, \\ Masahiro Asada ${ }^{1}$, Masashi Suzuki ${ }^{1}$, Junko Oki ${ }^{1}$ \\ and Toru Imamura ${ }^{1}$ \\ ${ }^{1}$ Signaling Molecules Research Laboratory, National Institute of Advanced Industrial Science and Technology (AIST), Higashi, Tsukuba 305-8566, Ibaraki, Japan \\ ${ }^{2}$ University of Tsukuba, Tennodai, Tsukuba, Ibaraki 305-8572, Japan \\ (Requests for offprints should be addressed to T Imamura, National Institute of Advanced Industrial Science and Technology (AIST), Central 6, 1-1-1 Higashi, \\ Tsukuba, Ibaraki 305-8566, Japan; Email: imamura-toru@aist.go.jp)
}

\begin{abstract}
The highly ordered process of wound healing involves the coordinated regulation of cell proliferation and migration and tissue remodeling, predominantly by polypeptide growth factors. Consequently, the slowing of wound healing that occurs in the aged may be related to changes in the activity of these various regulatory factors. To gain additional insight into these issues, we quantified the absolute copy numbers of mRNAs encoding all the fibroblast growth factors (FGFs), their receptors (FGFRs) and two other growth factors in the dorsal skin of young and aged mice during the healing of full-thickness skin excisional wounds. In young adult mice ( 8 weeks old), FGF7, FGF10 and FGF22 mRNAs were all strongly expressed in healthy skin, and levels of FGF7 and 10 but not 22 increased 2- to 3.5-fold over differing time courses after wounding. The levels of FGF9, 16, 18 and especially 23 mRNAs were moderate or low in healthy skin but
\end{abstract}

increased 2- to 33-fold after wounding. Among the four FGFRs, expression of only FGFR1 mRNA was augmented during wound healing. Expression of transforming growth factor- $\beta$ and hepatocyte growth factor was also high in healthy skin and was upregulated during healing. Notably, in aged mice (35 weeks old), where healing proceeded more slowly than in the young, both the basal and wound-induced mRNA expression of most of these genes was reduced. While these results confirm the established notion that FGFR2 IIIB ligands (FGF7 and FGF10) are important for wound healing, they also suggest that decreased expression of multiple FGF ligands contributes to the slowing of wound healing in aged mice and indicate the potential importance of further study of the involvement of FGF9, 16, 18 and 23 in the wound healing process.

Journal of Endocrinology (2005) 186, 273-289

\section{Introduction}

Wound healing is a highly ordered process that involves cell proliferation and migration, matrix protein synthesis and deposition, and tissue remodeling. This process has been divided into an inflammatory phase, a proliferative phase and a remodeling phase (Martin 1997, Singer \& Clark 1999), although the divisions are arbitrary and the phases overlap. Recently, a variety of cytokines and polypeptide growth factors have been shown to play key roles in each of these phases, with the latter involved in the regulation of cell migration, proliferation and differentiation, synthesis of matrix proteins, and secretion of matrix proteases and protease inhibitors (Martin et al. 1992, Martin 1997, Singer \& Clark 1999, Powers et al. 2000).

Among these mediators are several members of the fibroblast growth factor (FGF) family, which is comprised of twenty-two members in both human and mouse
(Powers et al. 2000, Itoh \& Ornitz 2004). The importance of these factors in wound healing was revealed, in part, by the finding that knocking out Fgf2 delays re-epithelialization following full-thickness excisional wounding (Ortega et al. 1998). Moreover, FGF7 (or keratinocyte growth factor, KGF), FGF10 (or KGF2), and possibly FGF22 act in concert via FGF receptor 2 IIIb (FGFR2 IIIb) to stimulate keratinocyte proliferation in both normal and wounded skin (Werner et al. 1994, Marchese et al. 1995, Igarashi et al. 1998, Ohuchi et al. 2000, Beyer et al. 2003), and overexpression of a dominant negative form of FGFR2 IIIb severely delays wound re-epithelialization in the transgenic mice (Werner et al. 1994). In addition, FGF1 (or acidic FGF), 2 (or basic FGF), 13 (or FGF-homologous factor-2; FHF2) and 18 are reportedly expressed in dermal and hair follicular cells (Marchese et al. 1995, Ortega et al. 1998, Kawano et al. 2004, 2005) and regulate skin regeneration and hair 
growth, although the activity of FGF13 is not yet clear. Finally, the overlapping but differential binding specificity of FGF family members to their respective receptors suggests that as yet uncharacterized FGFs may also contribute to wound healing.

Other growth factors expressed in tissues during wound healing include transforming growth factor- $\beta$ (TGF- $\beta$ ), hepatocyte growth factor (HGF), vascular endothelial cell growth factor and platelet-derived growth factor, all of which are thought also to be critical regulators governing the process of wound healing (Reed et al. 2003).

The changes in wound healing that occur in the aged are not fully understood. Unlike such pathological conditions as infection and diabetes, which impair wound healing, aging may simply reduce the speed at which an individual normally heals. In that case, it is likely that levels of regulatory factors and/or their responsiveness to wound-related stimuli are diminished. Indeed, decreased circulating and tissue levels of various regulatory factors have been reported with increasing age and are thought to contribute to alterations in angiogenesis that would ultimately lead to altered healing (Reed et al. 1998, Rivard et al. 1999).

Our aim in the present study was to use a mouse model to examine additional ways in which the FGF system is involved in wound repair, as well as the age-related changes in those processes. To accomplish this, we used an experimental system that enabled us to quantify absolute copy numbers of mRNAs encoding FGFs and their receptors, and to comprehensively profile the expression of all twenty-two FGFs (Itoh \& Ornitz 2004) and four FGF receptors (FGFRs) (Jaye et al. 1992) in the dorsal skin of young and aged mice at various stages of the healing process after full-thickness wounding.

\section{Materials and Methods}

Wound healing experiments: mice and skin sample preparation

Throughout this study, all animals received humane care that was in accordance with the guidelines of the National Institute of Advanced Industrial Science and Technology (AIST), and all protocols were approved by the animal experiment committee of AIST Central 6. For each set of wound healing experiments involving mRNA isolation, twenty-four 7- or 33-week-old male hairless $\left({ }^{h r} / h \eta\right)$ mice were obtained from Japan SLC (Hamamatsu, Japan) and were maintained on a standard laboratory diet and water which were available ad libitum. After conditioning (one week for 7-week-old and two weeks for 33-week-old mice), four mice were killed, and four dorsal skin samples $(8 \times 8 \mathrm{~mm}$ squares) were isolated and examined as the 'day 0 ' sample. In the remaining twenty mice, after anesthetization with an intraperitoneal injection of pentobarbital, four full-thickness round sections of dorsal skin, each $6 \mathrm{~mm}$ in diameter, were excised using a pair of scissors.
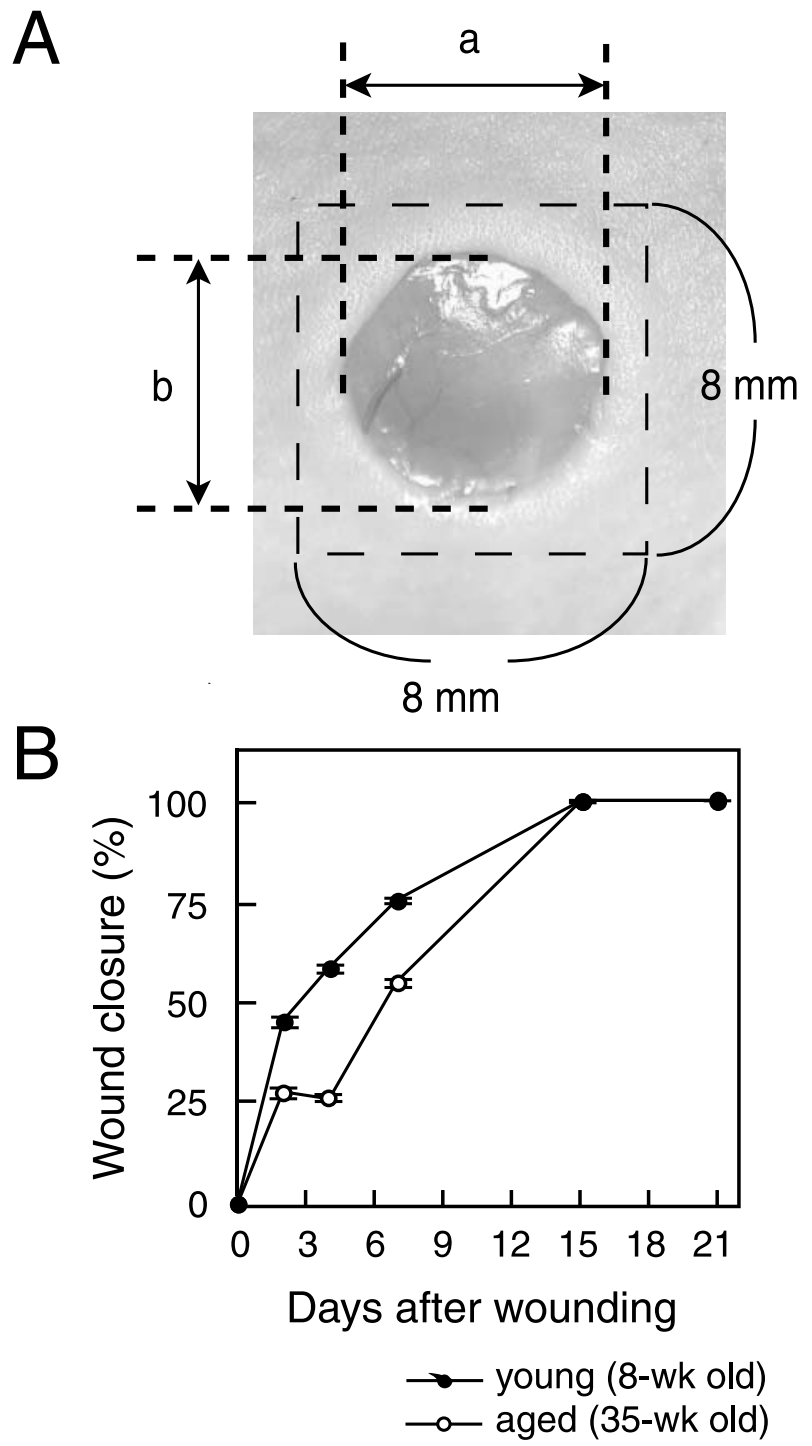

Figure 1 Healing of full-thickness excisional wounds in young and aged mice. Eight-week-old (young adult) or 35-week-old (aged) male hairless mice $\left({ }^{h r / h r}\right)$ were used in this study. (A) Eight mice were anesthetized, after which four portions of full-thickness dorsal skin (6 mm diameter) were excised from each mouse. The mice were then allowed to recover while being maintained on a standard laboratory diet and water available ad libitum in isolated cages. On the indicated days after wounding, the major $(\mathrm{a}, \mathrm{mm})$ and minor $(b, m m)$ axes of the wound were measured. These mice were kept alive throughout the entire experimental period. In a separate group of mice, the same procedure was followed, except that on the indicated days four mice were killed, and full-thickness skin samples $(8 \times 8 \mathrm{~mm})$ containing the wound were excised as shown and immediately processed for mRNA isolation. (B) The post-excision wound size was calculated using the formula, wound area $\left(\mathrm{mm}^{2}\right)=(\mathrm{a} \times \mathrm{b}) \times \pi / 4$. The area was then presented as percent closure by defining the initial area as $0 \%$ closure. Symbols represent means \pm S.E. $(n=8)$. The experiment was carried out twice to confirm the results. 
Table 1 Levels of expression of FGF and FGFR mRNAs in skin during wound healing in young mice ( 8 week old)

Highest mRNA expression

\begin{tabular}{|c|c|c|c|}
\hline & Copy number (/ng mRNA) & $\%$ of day 0 & $\begin{array}{l}\text { The day of the wound healing } \\
\text { process at which highest mRNA } \\
\text { expression was attained } \\
\text { (days after wounding) }\end{array}$ \\
\hline \multicolumn{4}{|l|}{ Gene } \\
\hline Fgf1 & 396 & 100 & 0 \\
\hline Fgf2 & 1577 & 109 & 15 \\
\hline Fgf3 & 151 & 100 & 0 \\
\hline Fgf4 & 18 & 100 & 0 \\
\hline Fgf5 & 638 & 147 & 2 \\
\hline Fgf6 & 139 & 124 & 21 \\
\hline Fgf7 & 13325 & 354 & 2 \\
\hline Fgf8 & 3 & 193 & 2 \\
\hline Fgf9 & 870 & 210 & 2 \\
\hline Fgf10 & 3038 & 207 & 2 \\
\hline Fgf11 & 1333 & 163 & 4 \\
\hline Fgf12 & 140 & 168 & 15 \\
\hline Fgf13 & 6525 & 121 & 2 \\
\hline Fgf14 & 10 & 106 & 2 \\
\hline Fgf15 & 17 & 885 & 2 \\
\hline Fgf16 & 1609 & 261 & 15 \\
\hline Fgf17 & 10 & 100 & $0 \& 21$ \\
\hline Fgf18 & 995 & 361 & 15 \\
\hline Fgf20 & 74 & 239 & 7 \\
\hline Fgf21 & 236 & 137 & 4 \\
\hline Fgf22 & 2,780 & 100 & 0 \\
\hline Fgf23 & 1,634 & 3296 & 2 \\
\hline Fgfr1 & 50457 & 159 & 15 \\
\hline Fgfr2 & 6,603 & 100 & 0 \\
\hline Fgfr3 & 19563 & 100 & 0 \\
\hline Fgfr 4 & 2,175 & 121 & 15 \\
\hline Gapdh & 1584644 & 100 & 0 \\
\hline b-actin & 963809 & 113 & 2 \\
\hline
\end{tabular}

The wounds were not covered and each mouse was allowed to recover in a separate clean cage. Then, on selected days (days 2, 4, 7, 15 and 21 after wounding) four mice were killed, and full-thickness skin samples (four $8 \times 8 \mathrm{~mm}$ squares per mouse containing the healing wounds (Fig. 1A)) were excised and processed for mRNA isolation. For the 8-week-old mice, the entire set of experiments was performed twice to confirm the reproducibility of the results. For the 35-week-old mice, only one set of experiments was performed due to the limited availability of the aged mice.

For wound closure analyses, eight mice were used for each set of experiments, and all the mice were kept alive throughout the entire experimental period. After wounding, the major $(\mathrm{a}, \mathrm{mm})$ and the minor $(\mathrm{b}, \mathrm{mm})$ axes of the 32 wounds on the eight mice (four wounds per mouse) were measured on the indicated days (Fig. 1A) (except on day 21 , when 16 wounds on four mice were measured). The post-excision wound area was evaluated using the formula: wound area $\left(\mathrm{mm}^{2}\right)=(\mathrm{a} \times \mathrm{b}) \times \pi / 4$. The average size of the four wound areas on each mouse was then calculated, and the data from the eight mice were subjected to statistical analysis. The area was then presented as percent closure by defining the initial area as $0 \%$ closure. Symbols represent means \pm standard errors (S.E.; $n=8$ ). The experiment was carried out twice for the 8-week-old mice and once for the 35-week-old mice.

For analysis of age-dependent changes in gene expression in healthy (i.e. unwounded) skin, sixteen 7-week-old male hairless mice were obtained from Japan SLC and were maintained on a standard laboratory diet and water which were available ad libitum. Four mice each were killed when they were $8,10,12$ or 14 weeks old, after which dorsal skin samples were isolated and processed for mRNA isolation.

\section{$m R N A$ preparation and reverse transcription}

Total RNA was prepared from skin samples using Isogen (Nippon Gene, Tokyo, Japan) according to the manufacturer's instructions, after which the mRNA was purified from the total RNA using an Oligotex-dT30 Super 
Fgf7 (Kgf)

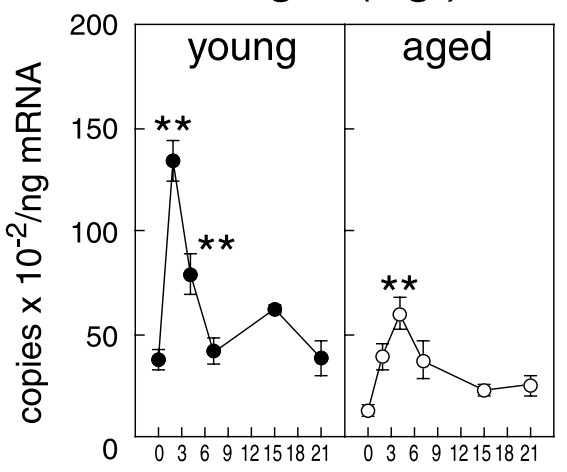

Fgf10 (Kgf2)

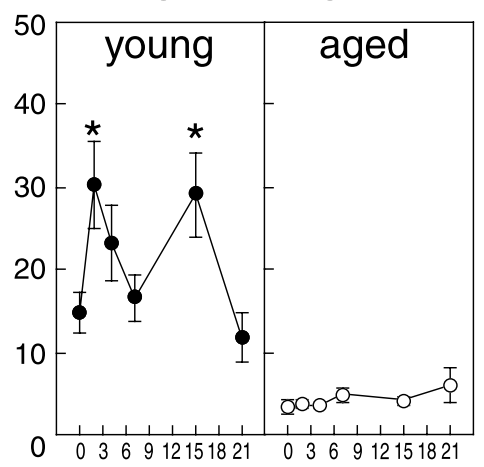

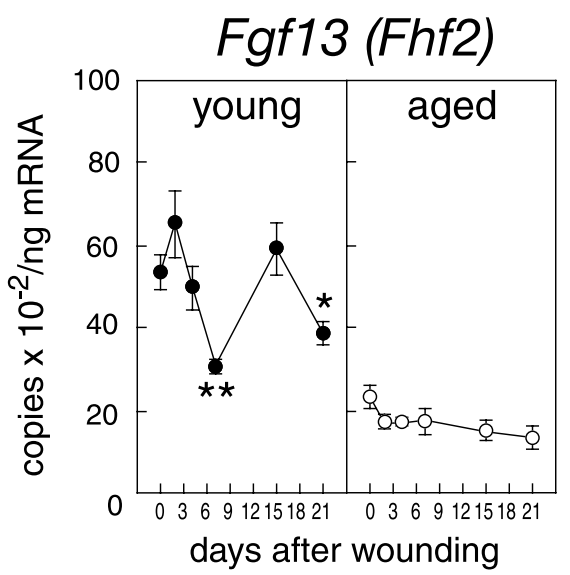

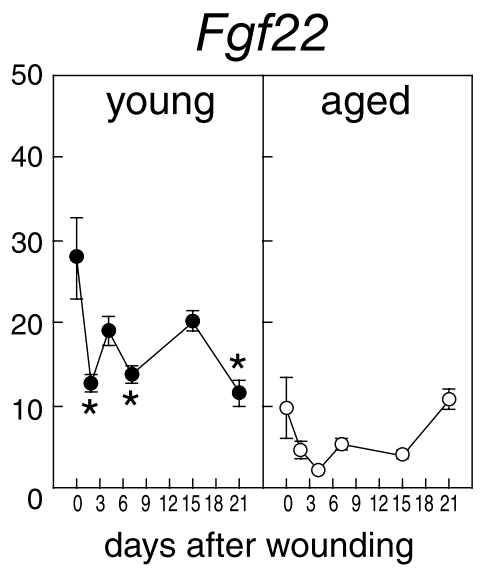

Figure 2 Strong expression of some FGF mRNAs in skin during wound healing. Twenty-four mice ( 8 or 35 weeks old) were used in each set of experiments. Initially, four mice were killed, and four portions of full-thickness dorsal skin $(8 \times 8 \mathrm{~mm})$ were excised from each mouse and examined as the 'day 0 ' sample. Wounds were made on the remaining 20 mice as described in the legend to Fig. 1; on the indicated days four mice were killed, and four dorsal skin samples containing the wounds $(8 \times 8 \mathrm{~mm})$ were isolated and processed for mRNA purification. Real-time PCR was then carried out as described in the Materials and Methods section. The experiment was carried out twice to confirm the results. Shown are levels of FGF mRNAs strongly expressed (over 4000 copies/ng mRNA at the respective peak level) during wound healing. The results for young mice are shown in the left panels and for aged mice in the right panels. Note that the $\mathrm{Y}$-axis for Fgf7 is different from the others. Symbols represent means \pm S.E. of quadruplicate samples; ${ }^{*} P<0 \cdot 05,{ }^{* *} P<0 \cdot 01$ compared with the respective value before wounding (day 0 ). The same set of experiments was carried out twice for each 8- or 35-week-old mouse to confirm the results.

mRNA purification kit (Takara Bio Inc., Osaka, Japan). Aliquots $(400 \mathrm{ng})$ of the purified mRNA were then reverse-transcribed in a total volume of $30 \mu \mathrm{l}$ using SuperScript II with Oligo $(\mathrm{dT})_{12-18}$ as the primer (Gibco BRL, Tokyo, Japan).

Quantification of mRNA copy number by real-time PCR

Specific primer sets were designed so that the levels of FGF mRNAs could be quantitatively analyzed using real-time PCR. The specificity of the primers was mainly ensured by using the whole mouse cDNA sequence as the background sequence (a new algorithm developed by Dr Akira Suyama at Tokyo University), and the same sets of primers were also used to clone the respective cDNA fragments that served as copy number references for quantification.

Real-time PCR was carried out in a Light Cycler (Roche Diagnostics, Basel, Switzerland) using $2 \mu \mathrm{l} \mathrm{RT}$ product diluted $1: 10$ as a template. The absolute copy 
Fgf2

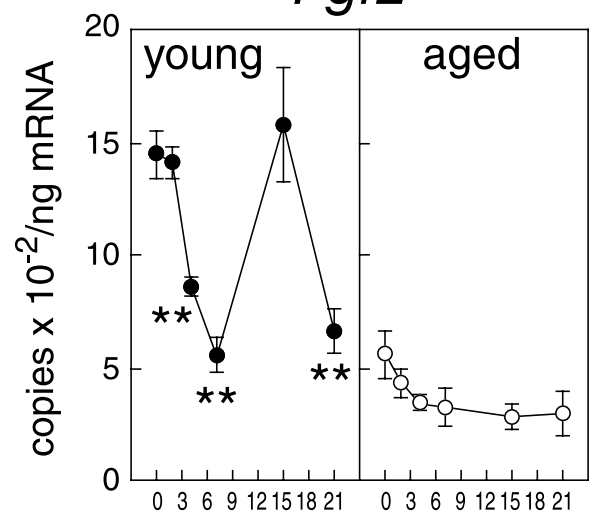

Fgf16

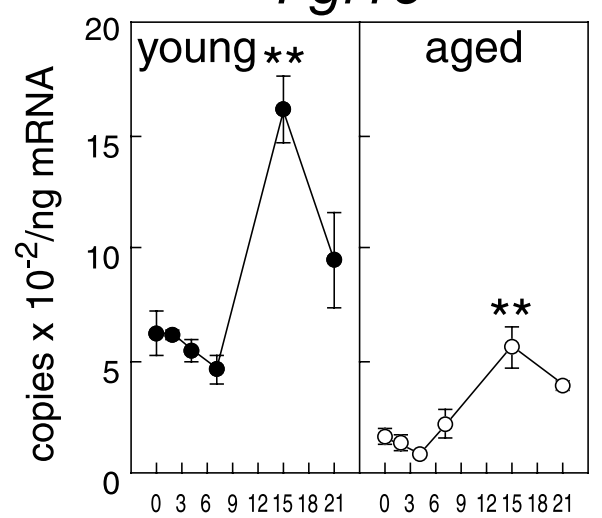

Fgf23

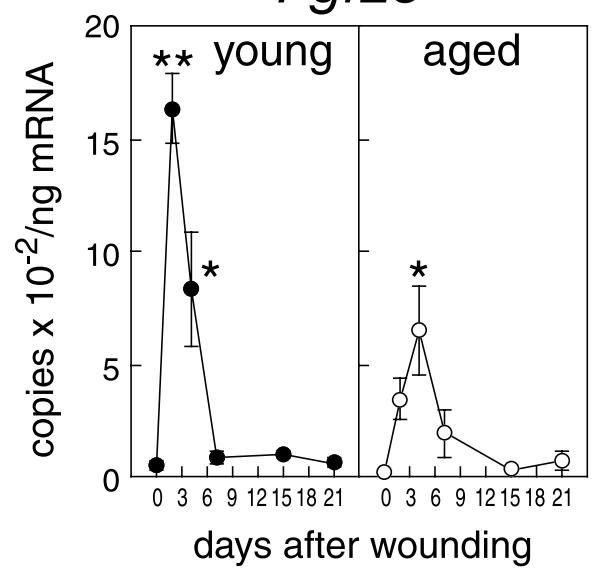

Fgf9

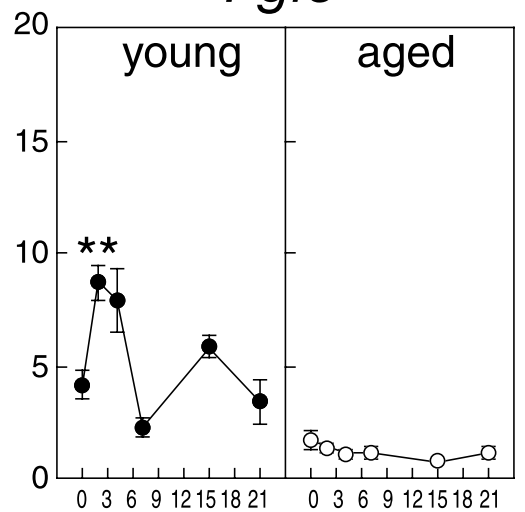

Fgf18

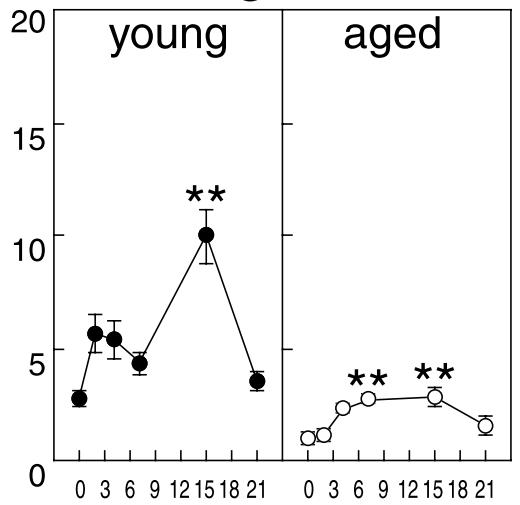

days after wounding
Fgf11

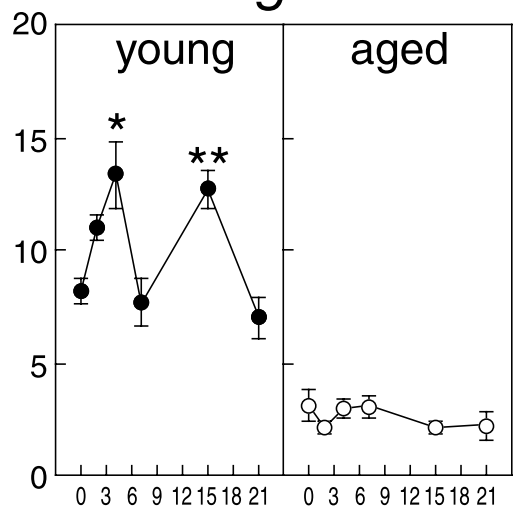

Figure 3 Moderate expression of some FGF mRNAs in skin during wound healing. Shown are levels of FGF mRNAs moderately expressed (over 1000 copies/ng mRNA at the respective peak level) during wound healing. The same set of experiments was carried out twice for each 8- or 35-week-old mouse to confirm the results. Note that the Y-axes are different from those in Fig. 2. Symbols and bars represent means \pm S.E. of quadruplicate samples for all the genes presented; ${ }^{*} P<0 \cdot 05,{ }^{*} P<0 \cdot 01$ compared with the respective value before wounding (day 0). 
Fgf1

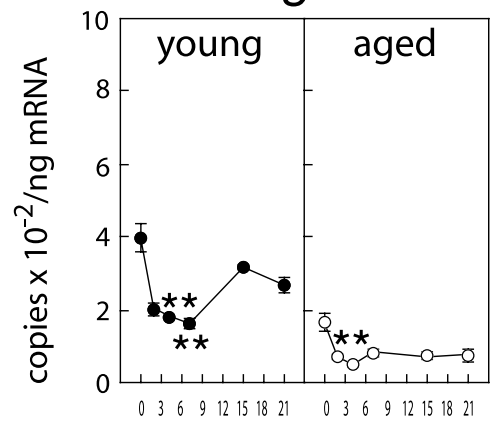

Fgf5

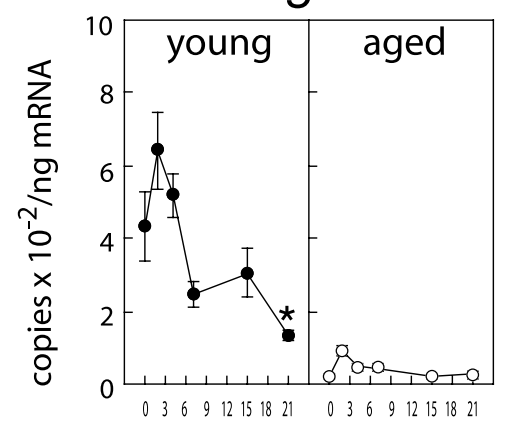

Fgf12

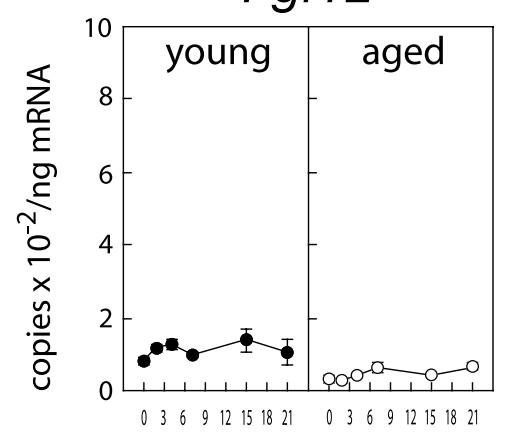

Fgf17

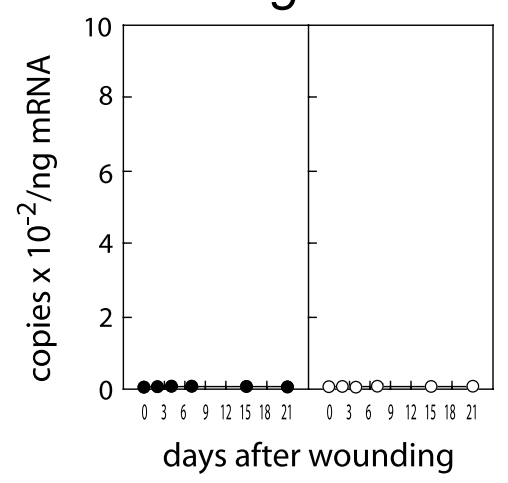

Fgf3

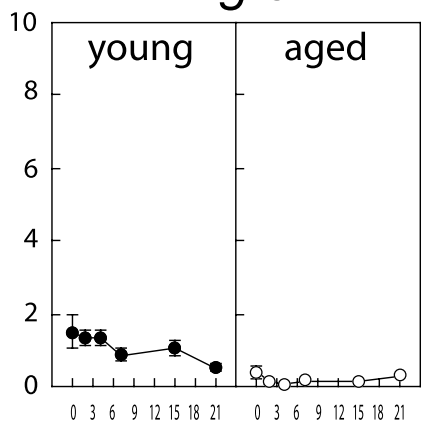

Fgf6

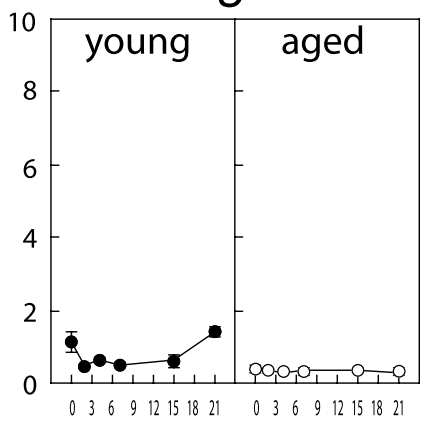

Fgf14

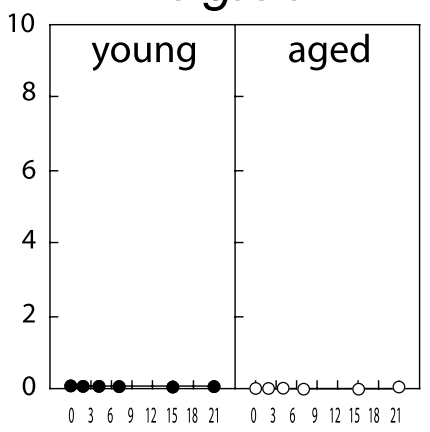

Fgf20

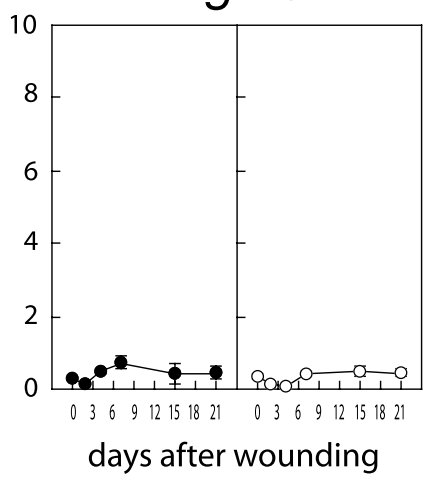

Fgf4

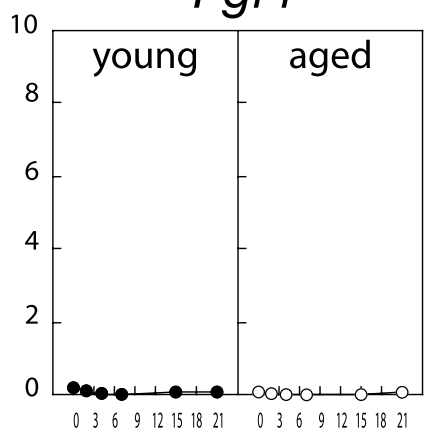

Fgf8

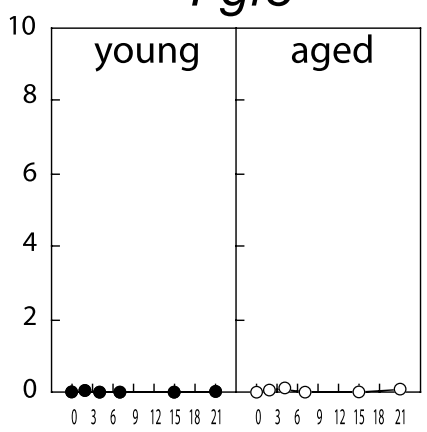

Fgf15

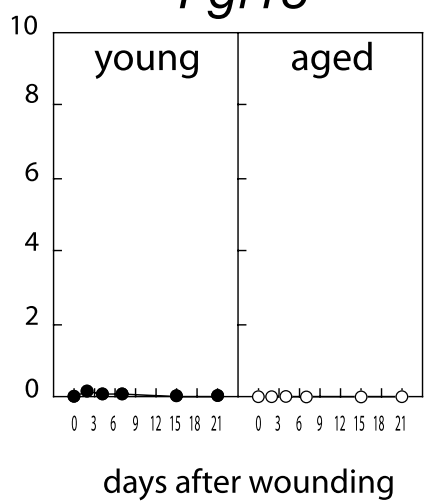


numbers of each FGF were determined using each respective plasmid DNA as a copy number reference (M Suzuki, J Oki \& T Imamura, unpublished observations). Cyber Green was used for quantification of the amplified DNA. Highly specific primers, as well as optimized annealing temperatures, elongation times and acquisition temperatures were employed in the Light Cycler reaction. To further ensure the specificity of the reaction conditions, at the end of the individual runs, the melting temperature (Tm) of the amplified product was measured to confirm its homogeneity. After the quantification procedure, the products were resolved by $2 \cdot 0 \%$ agarose gel electrophoresis to confirm that the reaction had amplified DNA fragments of the expected size.

For the evaluation of the mRNA, we included serially diluted DNA samples having the target cDNA sequence in the same Light Cycler run. This enabled the absolute copy number of the mRNA of interest to be calculated for the individual samples. We also evaluated the copy number of the housekeeping gene glyceraldehyde-3phosphate dehydrogenase (GAPDH) using the same procedures and confirmed that its abundance was within the expected range. The mRNAs prepared from each mouse were individually subjected to reverse transcription using Oligo $(\mathrm{dT})_{12-18}$ as the primer, and the absolute copy number was independently analyzed by real-time PCR as described above. From the results obtained from four mice under the same conditions, the means \pm S.E. of the mRNA copy numbers were calculated and presented in graphs. The significance of differences between groups was analyzed using Student's $t$-test.

\section{Results}

Healing of excisional full-thickness skin wounds in young and aged hairless mice

Earlier studies have shown that FGF1, 2, 5, 7, 10, 13 and 22 are all highly expressed in the skin of $\mathrm{C} 3 \mathrm{H} / \mathrm{HeN}$ mice and that many of them play important roles in skin and/or hair dynamics (DuCros et al. 1993, Hebert et al. 1994, Danilenko et al. 1995, Guo et al. 1996, Rosenquist \& Martin 1996, Mitsui et al. 1997, Ortega et al. 1998, Suzuki et al. 1998, Nakatake et al. 2001, Beyer et al. 2003, Steiling \& Werner 2003, Kawano et al. 2004, 2005). Moreover, we have found that expression of these factors is strongly affected by the progress of the hair growth cycle (Kawano et al. 2004, 2005). For that reason, we examined wound healing in the hairless mouse to eliminate the effect of the hair growth cycle on FGF expression. In addition, to eliminate the effect of menstruation, we used only male mice.

When we evaluated the closure of full-thickness excisional skin wounds on the dorsum of young adult (8-week-old) and aged (35-week-old) hairless mice, we found that the wounds closed to $50 \%$ of their original area by about day 3 in young mice and about day 6 in aged mice (Fig. 1B). Thus, even though at 35 weeks the life span of hairless mice is only partially completed, wound closure is substantially slower than in young adult mice. By day 15 after wounding, the wounds of both young and aged mice were completely closed (Fig. 1B).

\section{Expression profiles of FGFs and FGFRs in skin during wound healing}

To quantify the expression of mRNAs encoding all the various FGFs and FGFRs, we utilized an experimental system that involved designing a set of highly specific primers for each gene and using real-time PCR to measure the absolute copy number of the respective mRNAs (Table 1). We found that each gene studied was expressed at a distinct level in the healthy skin (day 0 ) of young adult hairless mice (Figs 2-6, left panels). FGF ligands that were previously shown to be expressed in skin (FGF1, 2, 5, 7, 10, 13 and 22) were indeed strongly expressed in the healthy skin of young mice (Figs 2, 3 and 4, day 0 in the left panels); in particular, levels of FGF7, 10, 13 and 22 mRNA were very high $(3760,1469,5375$ and 2780 copies/ng mRNA respectively). FGF2, 11 and 16 were also expressed at $>500$ copies/ng mRNA in healthy skin (Fig. 3, day 0 in the left panels). In addition, we found that levels of mRNAs encoding FGF7, 10 (Fig. 2, left panels), and FGF9, 11, 16, 18 and 23 (Fig. 3, left panels) were all significantly upregulated at various times during wound healing in young mice (within 21 days following wounding). As compared with the levels on day 0 , FGF5, 7, 9, 10 and 23 mRNAs were increased on day 2 after wounding, FGF11 mRNA was increased on day 4, and FGF7, 10, 11, 16 and 18 mRNAs were increased on day 15. Among these, increased levels of FGF7, 10 and 11 mRNA were observed on both day 2 (day 4 for FGF11) and day 15 (Figs 2 and 3, left panels). By contrast, levels of FGF2 and 22 mRNA were significantly reduced after wounding, but had returned to the levels seen before wounding by day 15 (Figs 3 and 2 respectively).

We found that mRNA encoding FGF23 (Fig. 3, left panel), which was expressed at low levels in healthy skin,

\footnotetext{
Figure 4 Weak expression of some FGF mRNAs in skin during wound healing. Shown are levels of FGF mRNAs weakly expressed (less than 1000 copies/ng mRNA at the respective peak level) during wound healing. The same set of experiments was carried out twice for each 8- or 35-week-old mouse to confirm the results. Note that the Y-axes are different from those in Fig. 3. Symbols and bars represent means \pm S.E. of quadruplicate samples for all the genes presented; ${ }^{*} P<0.05,{ }^{* *} P<0.01$ compared with the respective value before wounding (day 0).
} 

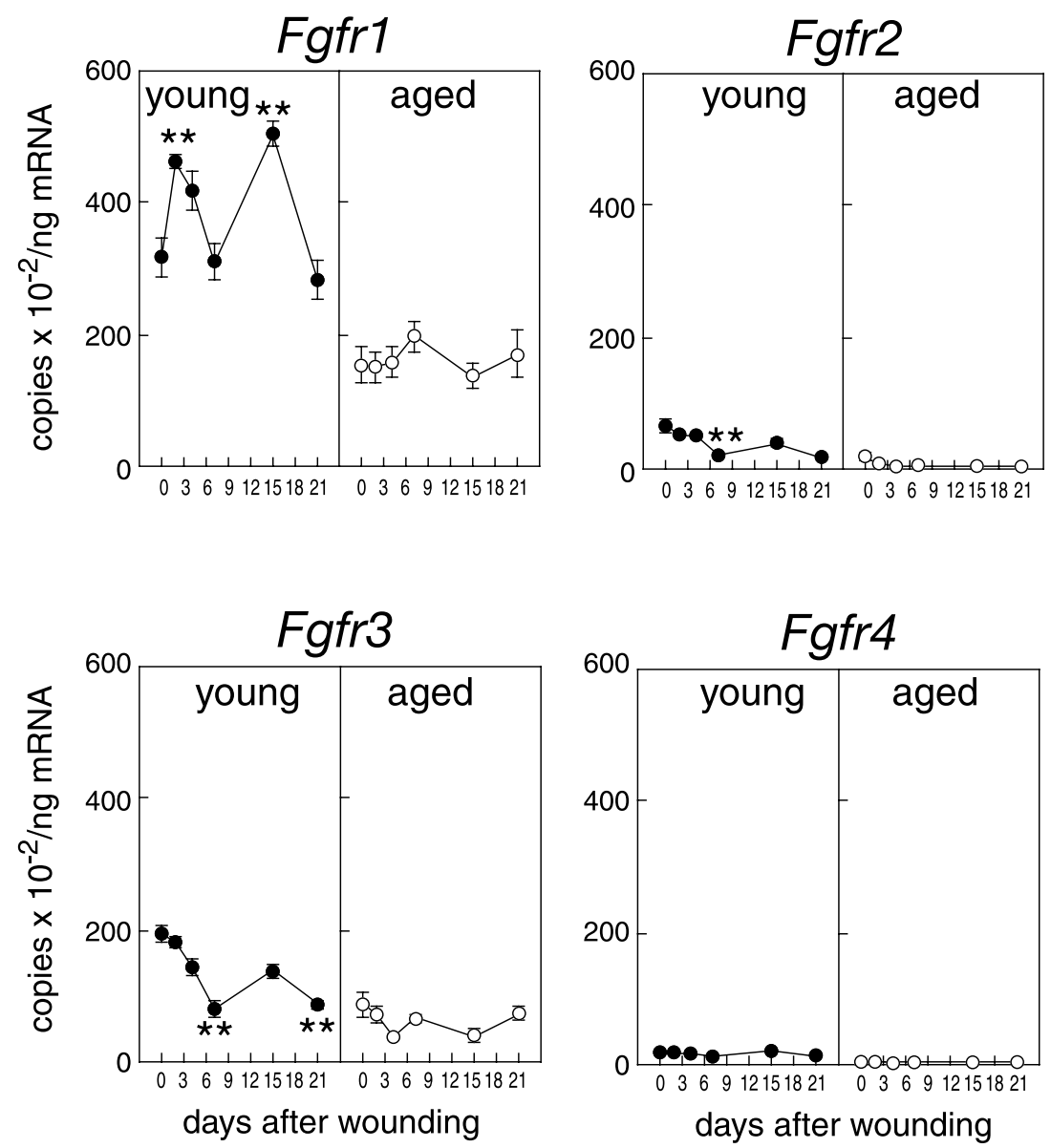

Figure 5 Expression of FGFR mRNAs in skin during wound healing. Symbols represent means \pm S.E. of qaudruplicate samples. The same set of experiments was carried out twice for each 8- or 35-week-old mouse to confirm the results. ${ }^{*} P<0 \cdot 05,{ }^{*} P<0 \cdot 01$ compared with the respective value before wounding (day 0).

was dramatically upregulated during wound healing. FGF23 mRNA was present in young healthy skin (day 0) at only 50 copies/ng mRNA, but by day 2 after wounding it was upregulated 33-fold to 1634 copies/ng mRNA, a level exceeding that of FGF2, which is considered important for wound healing (Fig. 3). Similarly, FGF18 mRNA was present in healthy skin at 275 copies/ng mRNA on day 0 , but was upregulated to 995 copies/ng mRNA on day 15. It was noted that many of the genes showed peaks in their expression on day 2 and/or day 15 after wounding (Figs 2-6). As expression levels of the housekeeping genes GAPDH and $\beta$-actin also changed during the healing process in young mice (Fig. 6, left panels), we present all the data on FGF expression without normalization (Figs 2-6).

FGF1, 3, 6, 12 and 20 are expressed at moderate levels in the young healthy skin and are not upregulated during wound healing (Fig. 4, left panels); in fact, FGF1 expression was downregulated during days 2-7 (Fig. 4). Other FGF ligand genes - i.e. FGF4, 8, 14, 15 and 17 - were nearly undetectable in both healthy and healing skin (Fig. 4).

Among the FGFR genes, Fgfr1 was most abundantly expressed in healthy skin, and was upregulated on days 2 and 15. Fgfr3 was also expressed at high levels, but its expression declined during the initial stage of healing. Fgfr2, a gene encoding the epithelium-specific receptor FGFR2c, was expressed at moderate levels in healthy skin, but was down-regulated during wound healing. Finally, Fgfr4 was the least abundantly expressed of the FGFR genes, and its level of expression did not change significantly during healing (Fig. 5, left panels).

Both TGF- $\beta 1$ and HGF are known to contribute significantly to wound healing. When we quantified their mRNA expression to determine whether it was upregulated during wound healing, we found that both TGF- $\beta 1$ and HGF mRNAs were expressed at high levels in healthy skin, and were then upregulated in response to wounding. Like that of FGF10 (Fig. 2, left panel), the expression of 

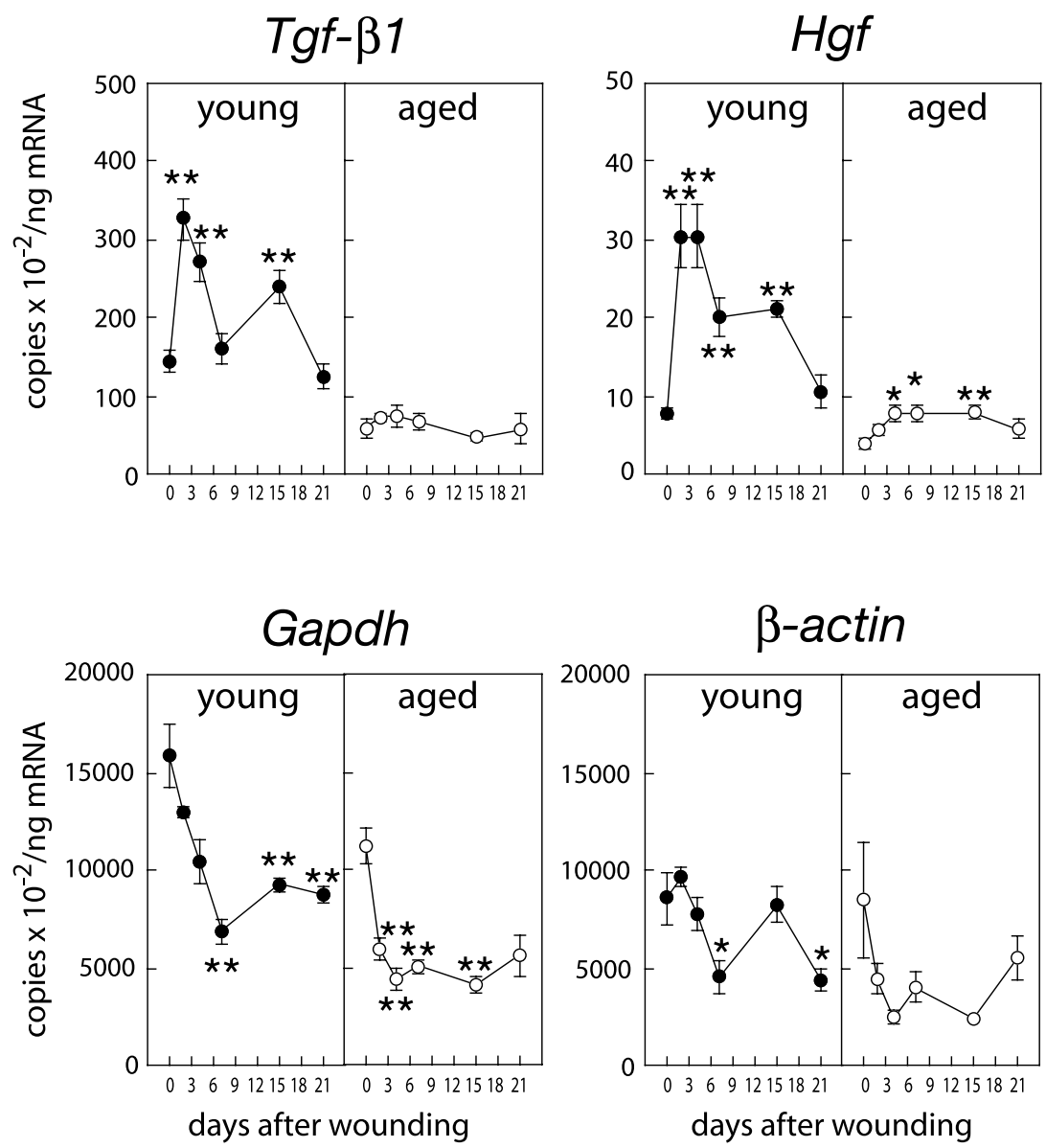

Figure 6 Expression of TGF- $\beta 1, \mathrm{HGF}, \mathrm{GAPDH}$ and $\beta$-actin mRNAs during wound healing. The same set of experiments was carried out twice for each 8- or 35-week-old mouse to confirm the results. Symbols and bars represent means \pm S.E. of quadruplicate samples for all the genes presented; ${ }^{*} P<0 \cdot 05,{ }^{* *} P<0 \cdot 01$ compared with the respective value before wounding (day 0 ).

TGF- $\beta 1$ mRNA peaked on days 2 and 15 (Fig. 6), whereas expression of HGF was upregulated early (day 2) and then remained elevated until day 15 (Fig. 6, left panel).

In aged mice, expression of many of the genes studied was downregulated in both healthy skin and after wounding (Figs 2-6, right panels and Table 2). All the FGFs that were upregulated during wound healing of young mice (FGF5, 7, 9, 10, 11, 16, 18 and 23) showed weaker expression in healthy skin and after wounding (Figs 2-4). Only expression of FGF21 was higher in aged mice than in young mice (Fig. 3). For some FGFs whose expression peaked on day 2 after wounding in young mice, the peak expression in aged mice was reduced, and the significant upregulation developed more slowly (FGF7 and 23; Figs 2 and 3 respectively). Furthermore, for FGF10 (Fig. 2), and for FGF2, 9 and 11 (Fig. 3), there was no clear upregulation in aged mice. Similarly, whereas a wound-induced increase in the expression of FGFR1, the dominant FGFR isoform in skin, was clearly observed on days 2 and 15 following wounding in the young mice, the change in its expression was much less clear in aged mice (Fig. 5). Likewise, the expression of both HGF and TGF- $\beta 1$ in healthy skin and after wounding was reduced in aged mice (Fig. 6), as was reported previously (Reed et al. 1998).

Age-dependent changes in the expression of FGFs and FGFRs in healthy skin

Because we observed that not only wound responses but also basal expression levels of many FGF and FGFR genes differed between 8 - and 35-week-old mice, we analyzed the age-dependent changes in their basal expression over the course of 6 weeks, from the time they were 8 weeks old until they were 14 weeks old. Seven-week-old mice with the same birthday were obtained and kept until they 
Table 2 Levels of expression of FGF and FGFR mRNAs in skin during wound healing in aged mice (35 week old)

\section{Highest mRNA expression}

\begin{tabular}{|c|c|c|c|}
\hline & Copy number (/ng mRNA) & $\%$ of day 0 & $\begin{array}{l}\text { The day of the wound healing } \\
\text { process at which highest mRNA } \\
\text { expression was attained } \\
\text { (days after wounding) }\end{array}$ \\
\hline \multicolumn{4}{|l|}{ Gene } \\
\hline Fgf1 & 164 & 100 & 0 \\
\hline Fgf2 & 558 & 100 & 0 \\
\hline Fgf3 & 41 & 100 & 0 \\
\hline Fgf4 & 8 & 100 & 0 \\
\hline Fgf5 & 93 & 417 & 2 \\
\hline Fgf6 & 39 & 100 & 0 \\
\hline Fgf7 & 5973 & 472 & 4 \\
\hline Fgf8 & 9 & 1330 & 4 \\
\hline Fgf9 & 167 & 100 & 0 \\
\hline Fgf10 & 612 & 191 & 21 \\
\hline Fgf11 & 310 & 100 & 0 \\
\hline Fgf12 & 65 & 204 & 21 \\
\hline Fgf13 & 2311 & 100 & 0 \\
\hline Fgf14 & 3 & 233 & 21 \\
\hline Fgf15 & 2 & 981 & 4 \\
\hline Fgf16 & 558 & 351 & 15 \\
\hline Fgf17 & 9 & 139 & 21 \\
\hline Fgf18 & 281 & 277 & 15 \\
\hline Fgf20 & 50 & 134 & 15 \\
\hline Fgf21 & 660 & 100 & 0 \\
\hline Fgf 22 & 1071 & 111 & 21 \\
\hline Fgf23 & 652 & 3858 & 4 \\
\hline Fgfr1 & 19748 & 128 & 7 \\
\hline Fgfr2 & 1797 & 100 & 0 \\
\hline Fgfr3 & 8857 & 100 & 0 \\
\hline Fgfr 4 & 428 & 138 & 4 \\
\hline Gapdh & 1119569 & 100 & 0 \\
\hline b-actin & 845131 & 100 & 0 \\
\hline
\end{tabular}

were $8,10,12$ or 14 weeks old, after which the levels of mRNA expression in their healthy skin were analyzed. As shown in Figs 7-9, even within this short period, the expression of some of the genes changed significantly, although others did not. The mRNA expression of FGF11, 13 (Fig. 7), 1 and 5 (Fig. 8) and FGFR1, R2 and R3 (Fig. 9) was significantly lower at 14 weeks than at 8 weeks, which is in good agreement with the difference seen between the healthy skin of 35-week-old and 8-week-old mice (Figs 2, 3 and 5). A similar decline was also seen in the expression of FGF22 mRNA (not shown). It thus appears that the age-dependent decline in mRNA expression of some FGF and FGFR genes begins relatively early in life.

\section{Discussion}

The healing of skin wounds progresses through sequential and overlapping phases of inflammation, tissue repair, formation of new tissue, re-epithelialization and remodeling (Paddock et al. 2003). At the cellular level, each phase is directed by the coordinated interaction of several types of cells, including inflammatory cells and such native skin cells as fibroblasts, keratinocytes and vascular endothelial cells. At the molecular level, cytokines regulate inflammatory cells during the early stages of wound healing, and throughout the process polypeptide growth factors play dominant roles in the regulation of the proliferation and differentiation of native skin cells and the

Figure 7 Age-dependent changes in the levels of strongly and moderately expressed FGF mRNAs in healthy skin. Seven-week-old male hairless mice were maintained on a standard laboratory diet and water available ad libitum for varying periods. When they reached 8,10 , 12 or 14 weeks of age, four mice were killed, and dorsal skin samples were separately collected and processed for mRNA purification and quantification as described in the legend to Fig. 2. The same FGFs that are presented in Figs 2 and 3 are shown. Symbols represent means \pm S.E. of quadruplicate samples; ${ }^{*} P<0 \cdot 05,{ }^{*} P<00 \cdot 01$ compared with the value at 8 weeks. 

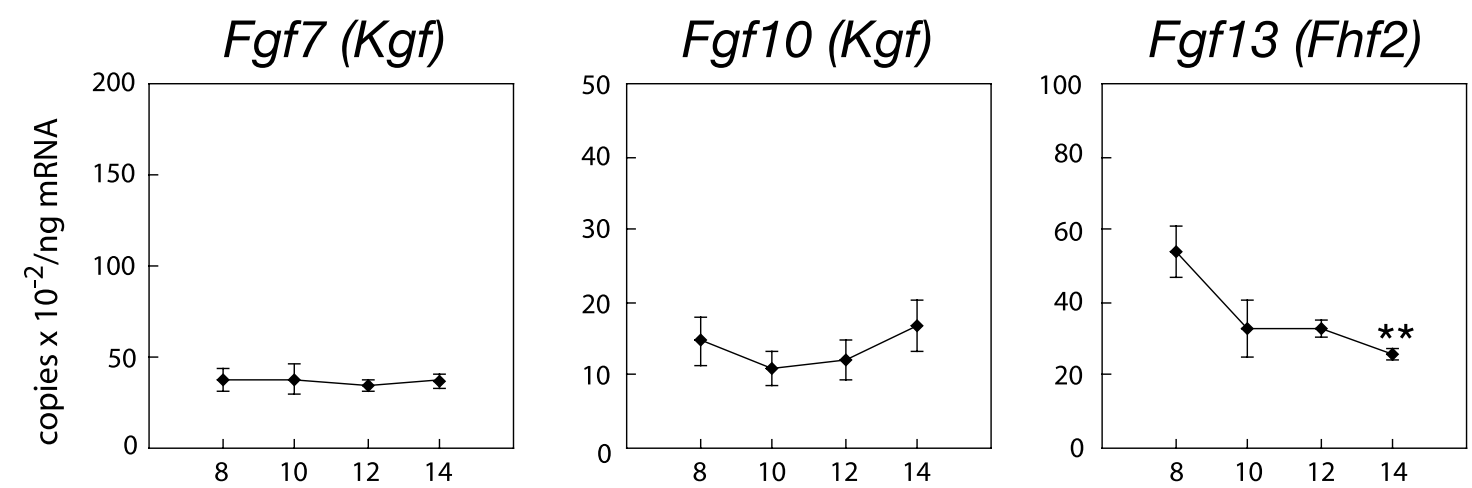

Fgf22
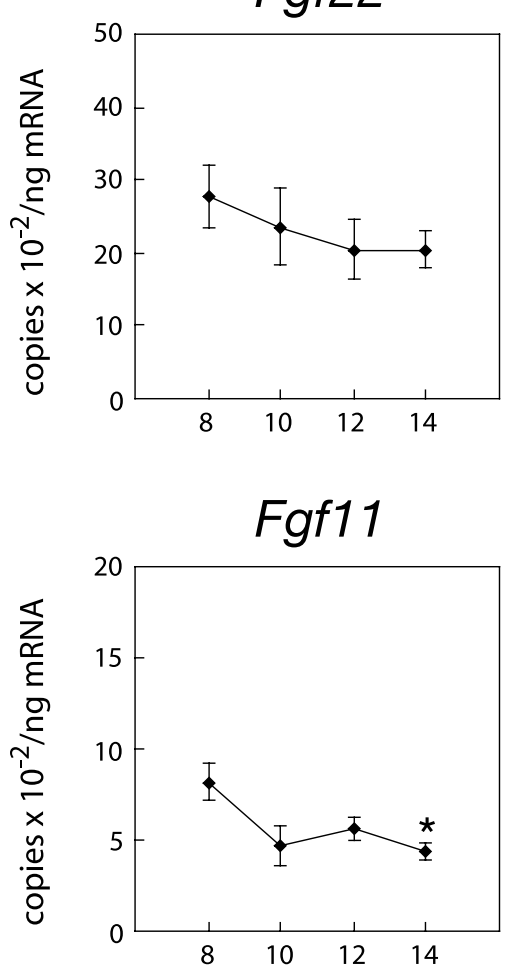

Fgf21

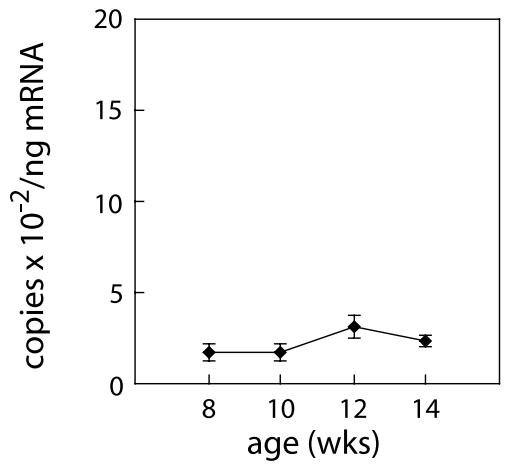

Fgf2

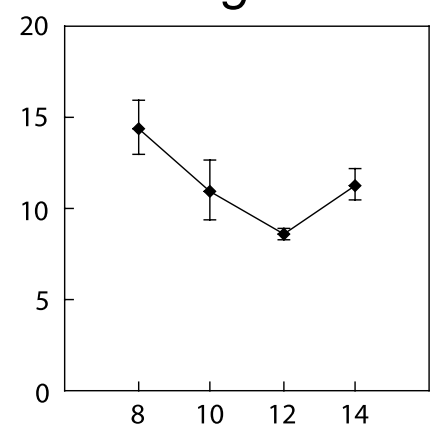

Fgf16

Fgf9

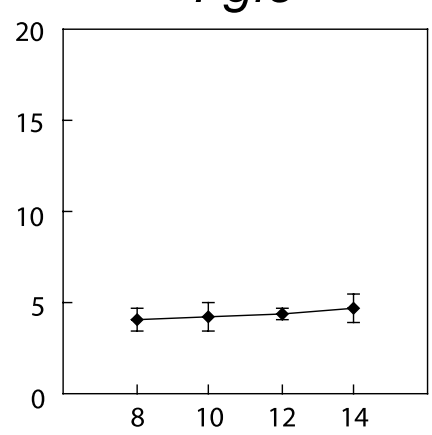

Fgf18

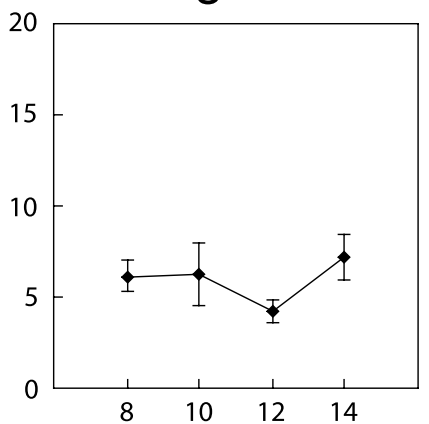

Fgf23
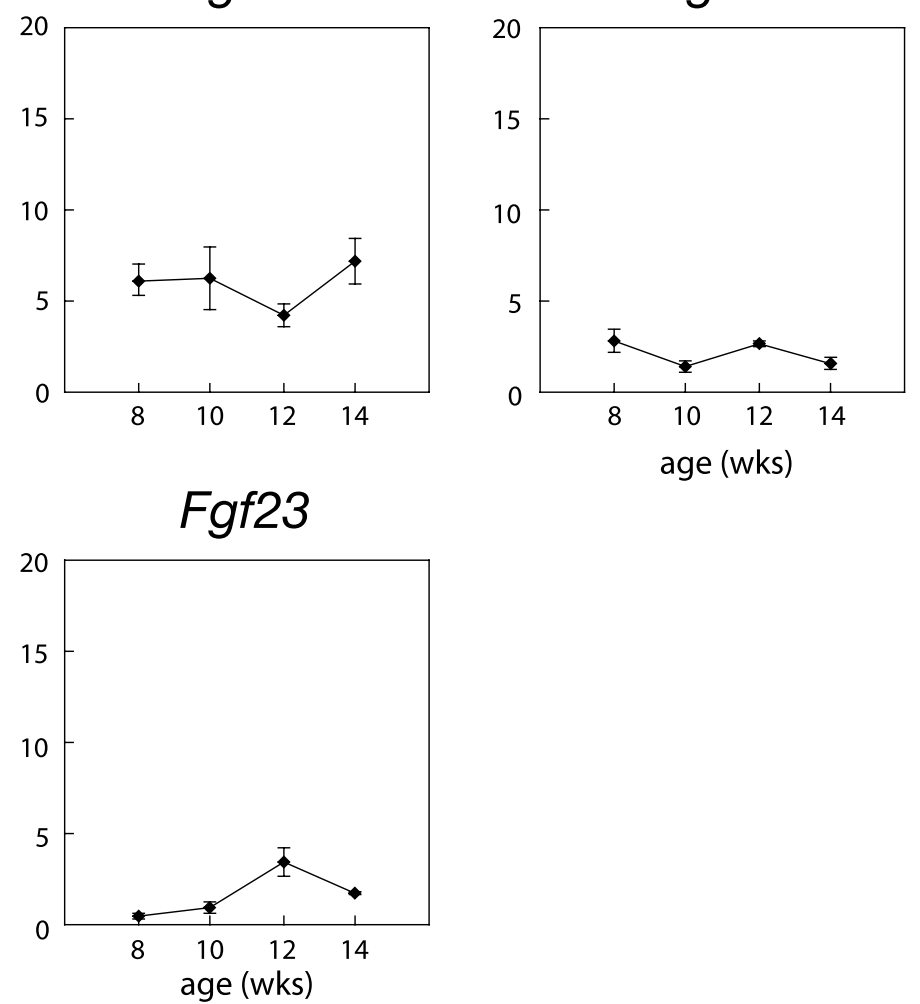

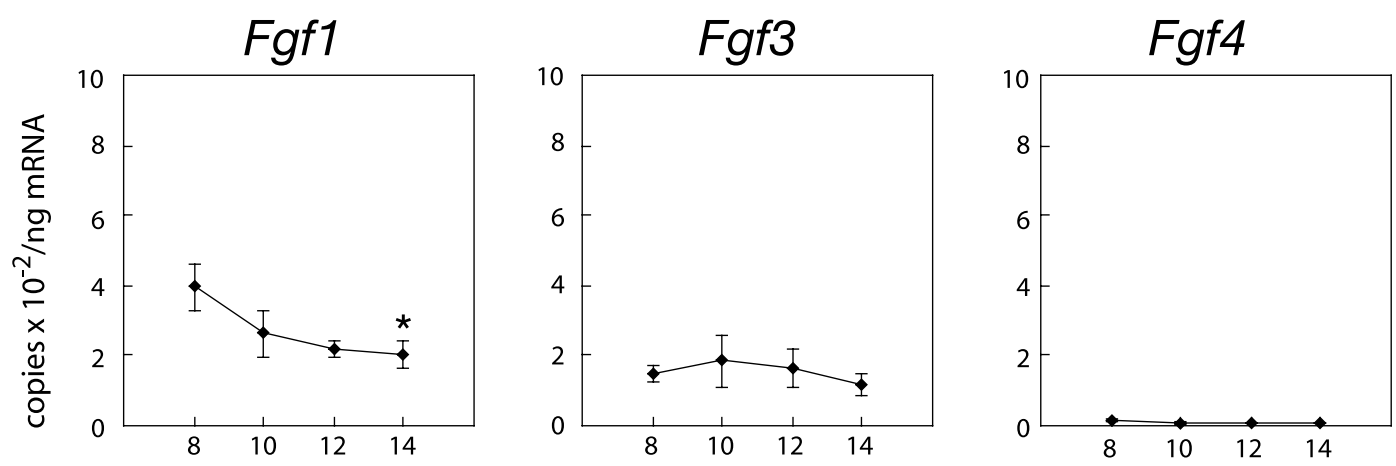

Fgf5

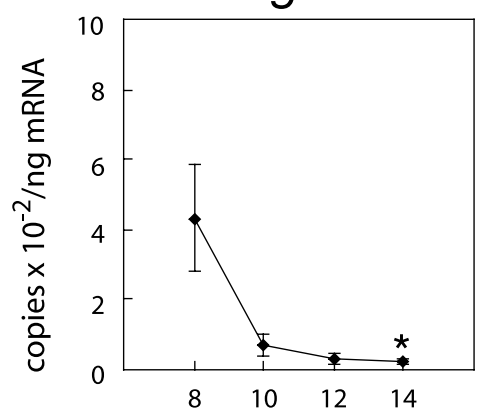

Fgf6

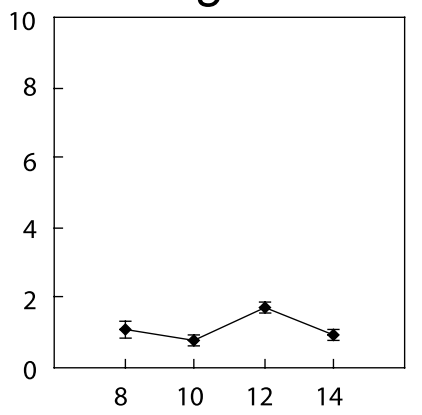

Fgf8

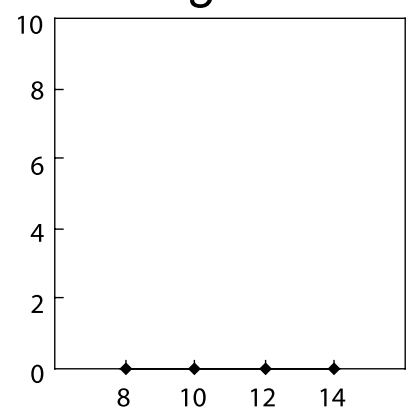

Fgf12

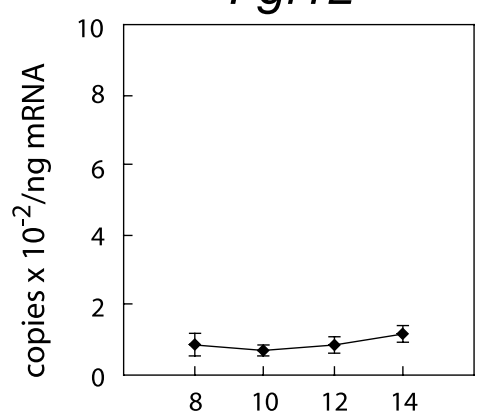

Fgf14

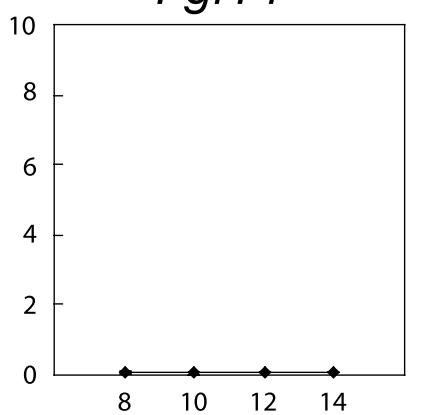

Fgf15

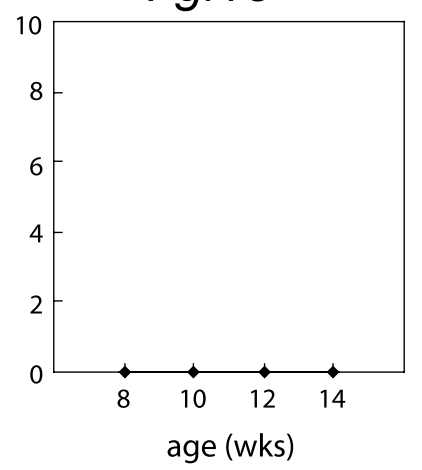

Fgf17

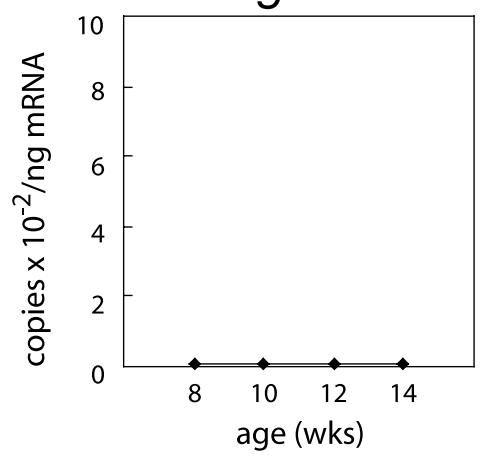

Fgf20

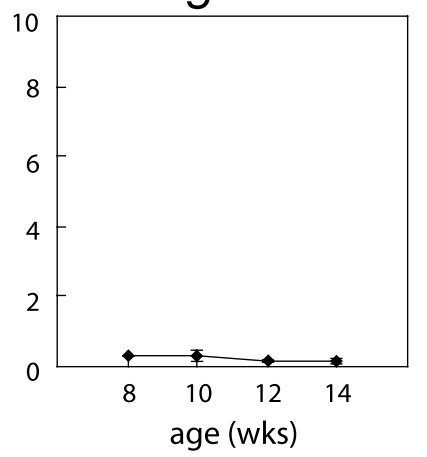

Figure 8 Age-dependent changes in the levels of weakly expressed FGF mRNAs in healthy skin. Experiments were performed as described in the legend to Fig. 7. The same FGFs that are presented in Fig. 4 are shown. Symbols represent means \pm S.E. of quadruplicate samples; ${ }^{*} P<0 \cdot 05$ compared with the value at 8 weeks. 
Fgfr1

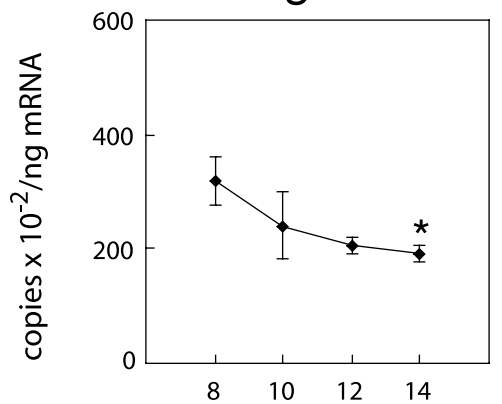

Fgfr3

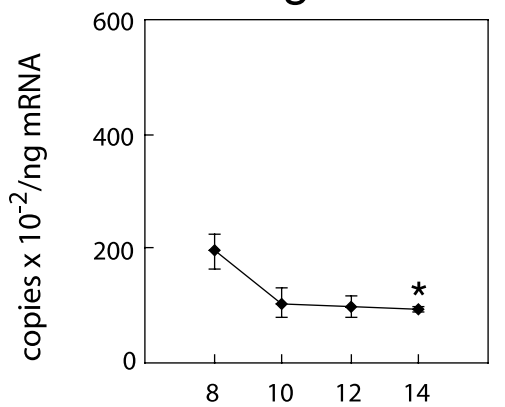

Tgf- $\beta 1$

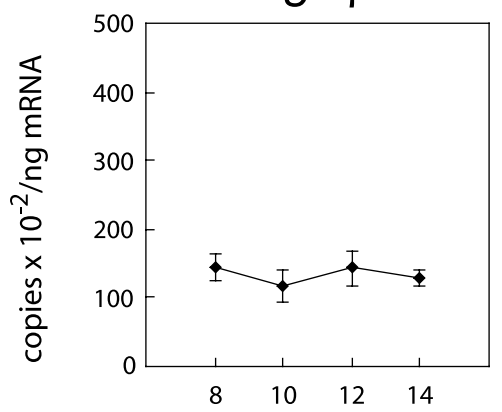

Gapdh

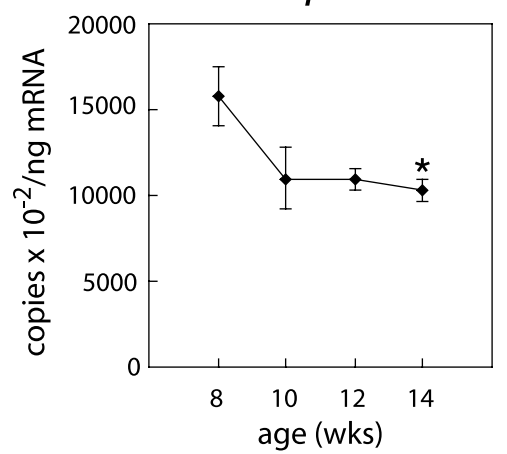

Fgfr2

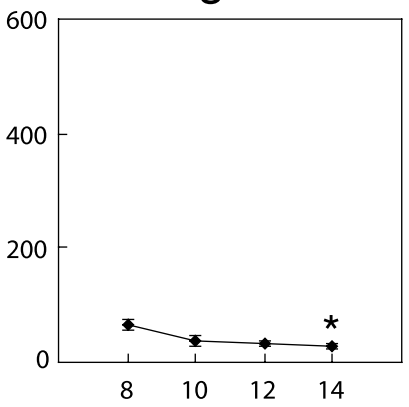

Fgfr4

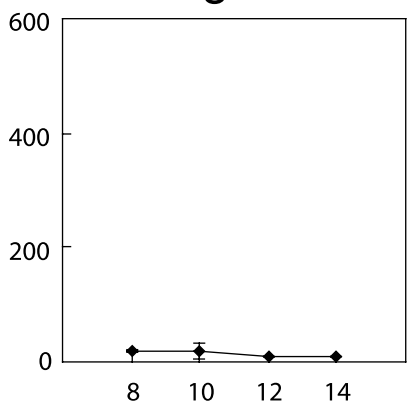

Hgf

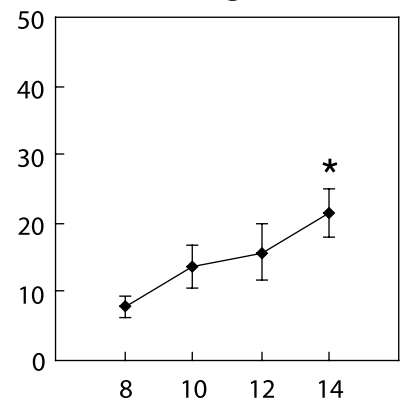

$\beta$-actin

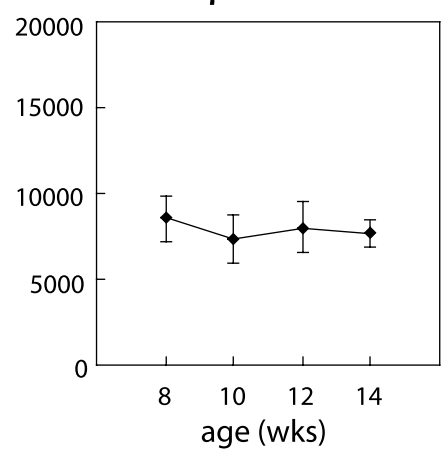

Figure 9 Age-dependent changes in the expression of FGFRs, TGF- $\beta 1$, HGF, GAPDH and $\beta$-actin mRNAs in healthy skin during wound healing. Symbols represent means \pm S.E. of quadruplicate samples; ${ }^{*} P<0 \cdot 05$ compared with the value at 8 weeks. 
synthesis of extracellular matrix. Among these mediators, the importance of several FGFs and their receptors is already established. But not all FGF family members have been analyzed qualitatively and/or quantitatively for their contribution. Furthermore, the dynamic aspects of their contribution, reflected by the time-dependent changes in their expression during wound healing, and during aging, have not yet been systematically addressed.

Quantification of mRNA copy numbers for all twentytwo FGFs in untreated and wounded mice revealed those members that are strongly expressed in healthy skin and/or healing skin. The utility of this experimental system in the pursuit of healing-related growth factors is supported by our results with growth factors already known to be involved in wound healing (TGF- $\beta$ and HGF). Indeed, TGF- $\beta$ is one of the most studied growth/differentiation factors in the field of wound healing research. One study on TGF- $\beta 1$-deficient mice demonstrated that the absence of this mediator can be compensated for at early stages of wound repair but not at late stages (Brown et al. 1995), and mice treated with a neutralizing anti-TGF- $\beta 1$ antibody showed severely impaired late stage wound repair (Shah et al. 1999). In addition, neutralization of HGF led to retardation of wound healing with decreased neovascularization and granulation tissue formation (Yoshida et al. 2003). These results are consistent with our finding that expression of both TGF- $\beta 1$ and HGF mRNA is strongly enhanced after wounding. Furthermore, our finding that the first peak in post-wound expression occurred on day 2 , when inflammatory cells are abundant within the wounds, is consistent with the earlier finding that large amounts of TGF- $\beta 1$ are found in platelets, macrophages, fibroblasts and keratinocytes which are all present within wounds at that time (Roberts \& Sporn 2001). Thus, quantification of growth factor mRNA levels provides significant information about the possible involvement of these cells in the wound healing process.

The keratinocyte-specific FGFs (FGF7, 10 and 22) were all strongly expressed in the healthy skin of young mice (>1400 copies/ng mRNA on day 0; Fig. 2); however, following wounding only FGF7 and FGF10 mRNA expression increased, while expression of FGF22 mRNA declined to approximately half its level in healthy skin (Fig. 2). This might reflect a difference in their expressing cells. Whereas FGF22 is expressed by epidermal and hair follicular keratinocytes, FGF7 and 10 are normally expressed by dermal fibroblasts and other mesenchymal cells (Nakatake et al. 2001, Beyer et al. 2003). After wounding, FGF7 is strongly expressed by dermal fibroblasts at the wound edge and by hypodermal cells (Werner et al. 1994). FGF7 is also expressed by dendritic epidermal $\mathrm{T}$ cells that may recognize damaged keratinocytes (Jameson et al. 2002). In periapical lesions FGF7expressing cells are found in the connective tissue stroma close to the foci of inflammatory cells (Gao et al. 1996). Thus, while large numbers of native skin cells are normally lost at the site of full-thickness wounding, inflammatory cells, cells adjacent to granulation tissue or inflammatory cells and newly proliferating cells may become the major source of growth factors. This notion is supported by our observation that the first peak in the expression of FGF7 and 10 was on day 2 (Fig. 2), when inflammation is prominent, although it is not yet established whether FGF10 is expressed by the same cell population as FGF7. The second peak in the expression of FGF7 and 10 mRNA occurred on day 15 and may reflect their expression by a large number of newly formed dermal fibroblasts. In that regard, whereas inhibition of signaling via FGFR2 IIIb, the receptor for FGF7 and FGF10, severely delayed wound re-epithelialization in transgenic mice (Werner et al. 1994), FGF7-deficient mice showed no defect in incisional wound healing (Guo et al. 1996). Taken together with the present findings, this suggests that in wild-type mice FGF7 and 10 act in concert to stimulate FGFR2 IIIb signaling to keratinocyte proliferation.

We found that the mRNA expression of FGFR1, the primary receptor mediating FGF mitogenic signaling, was the highest among FGF receptors in healthy skin, and that its expression was upregulated in response to wound healing. The degree to which FGFR1 is required for wound healing has not been well studied in mice because deletion of Fgfr1 or Fgfr2 is lethal in utero. In a zebrafish wound model, however, it was found that Fgfr1 is expressed in mesenchymal cells underlying the wounded epidermis during blastema formation, and that inhibition of Fgfr1 expression blocks blastema formation without obvious effects on wound healing (Poss et al. 2000). It is therefore suggested that, in mouse cutaneous wound healing, FGFR1 plays an important role in granuloma formation and the subsequent regeneration of dermis, including fibroblasts and vascular cells, but not in re-epithelialization, which is governed by FGFR2 IIIb. If that is the case, the observed reduction in basal FGFR1 mRNA expression and its sluggish response to wounding may account, at least in part, for the delayed wound healing seen in aged mice. FGFR 3 and FGFR 4 are expressed at lower levels than FGFR1, and their involvement in cutaneous wound healing is less well understood, although FGFR3 is thought to play crucial roles in bone development and repair (Nakajima et al. 2003).

Remarkably, expression of FGF23 mRNA was increased 33-fold on day 2 after wounding in young mice, but although we performed both in situ mRNA hybridization and immunohistochemical staining of FGF23, we have not yet located the site of its expression (A Komi-Kuramochi \& T Imamura, unpublished observations). Still, the observation that its expression peaked on day 2 after wounding, like that of FGF7, suggests that FGF23 mRNA may also be expressed by cells adjacent to inflammatory cells or by the inflammatory cells recruited to wound sites. The gene encoding FGF23 ( $\left.f_{g} f 23\right)$ was first identified using mutations associated with autosomal 
dominant hypophosphatemic rickets, an inherited phosphate wasting disorder (Bai et al. 2003). FGF23 was shown to inhibit renal tubular phosphate transport and to be a substrate of the endopeptidase PHEX (phosphateregulating gene with homologies to endopeptidases on the $\mathrm{X}$-chromosome); the phosphate wasting is the result of mutations at the cleavage site (Bowe et al. 2001). Although the timing of its strong expression in wounds may suggest a role at the early stages of wound healing, whether FGF23 regulates growth and differentiation of local cells or acts as a humoral messenger, exerting some remote effect on phosphate waste or vitamin D metabolism, is currently unknown and is a subject for future study.

It has generally been thought that FGF2, perhaps the most extensively studied FGF family member, is deeply involved in wound healing. Indeed, FGF2 knockout mice exhibit delayed healing and re-epithelialization when challenged with full-thickness excisional wounding (Bikfalvi et al. 1997). Although it is expressed at a comparatively high level in the healthy skin (day 0, Fig. 3), its expression significantly declined during the first week after wounding, which paralleled the decline in GAPDH expression, and then increased, so that by day 15 it had reached its initial level. This suggests FGF2 may contribute to wound healing at later stages.

The changes in wound healing that occur in the aged have been extensively studied from many viewpoints, but even the simple question of whether aging merely reduces the speed at which an individual normally heals has not yet been fully answered. Aging affects both the morphology and function of skin. In aged humans, cells comprising the epidermis become more variable in size, shape and orientation, and their turnover time increases by about $50 \%$ (Reed et al. 2003). There is also a generalized atropy and thinning of the dermis due to reductions in cell number and changes in the surrounding matrix (Reed et al. 2003). In addition, it was found in aged animals that keratinocytes, fibroblasts and endothelial cells all show less proliferation and migration within wounds, and there is less synthesis of matrix (Reed et al. 2003). Although the 'aged' mice we used were only 35 weeks old, which does not put them at a terminal point in their life span, they nevertheless exhibited a slowing in wound healing (Fig. 1). As the healing of skin wounds involves a complex system of integrated molecular signals and interactions among many different cell types within the wound, an analysis of growth factor expression may provide useful information about age-dependent changes. We found that expression of all of the keratinocyte-specific FGFs (FGF7, 10 and 22) is diminished in aged mice, even in healthy skin, and that the post-wound upregulation of expression was less pronounced and slower than in the young mice. In that regard, the reduced expression of FGF7 seen in glucocorticoid-treated mice and genetically diabetic mice with impaired healing suggests that a defect in FGF7 regulation might underlie various wound-healing disorders
(Brauchie et al. 1995) and highlights the potential importance of reduced FGF7 expression in the slowed healing seen in aged mice. Furthermore, expression of FGF10 was not augmented in wounded skin of aged mice (Fig. 2), which could contribute significantly to the slowing of re-epithelialization seen in aged mice. The potent mitogens for mesodermal- and neuroectodermaloriginated cells (FGF1, 2, 9, 16 and 18) were also only weakly expressed in aged skin, and the increase in FGF2 expression seen in the late stage of healing (day 15) in young mice was absent in aged mice (Fig. 3). Together with the reduced expression of FGFR1, the major FGF receptor in skin, which has the capacity potently to signal for cellular proliferation, and the reduced expression of FGFR2, one subclass of which (FGFR2 IIIb) is the sole receptor for FGF7 and 10, our findings suggest that changes in FGF expression may significantly affect proliferation of the keratinocytes, fibroblasts, preadipocytes and vascular cells that constitute the epidermis, dermis and hypodermis.

We found that an age-dependent decline in the expression of some FGF and FGFR genes in healthy skin could be observed in mice as young as 14 weeks of age, indicating that at least some of these changes occur gradually, not abruptly, during the life span of the mouse. On the other hand, expression of some genes (e.g. FGF10) did not change during this short period ( 8 weeks to 14 weeks of age), although their levels were significantly reduced by 35 weeks. Apparently, changes in the expression of those genes begin at a later stage of life.

In summary, we observed striking declines in both the number of wound-responsive FGF and FGFR genes and the strength of the wound-induced expression of those genes that remained responsive in aged mice. This large change in FGF gene expression could account, at least in part, for the age-related slowing of wound healing in mice. The current study provides basic information on the mRNA levels of FGFs and FGFRs in young and aged adult mice. Using this information as the foundation, functional studies aimed at clarifying the function of each FGF in healthy skin and during wound healing will be possible.

\section{Acknowledgements}

We thank Prof. Tadashi Baba of the University of Tsukuba for his support of the graduate study of Mitsuko Kawano, Prof. Akira Suyama of Tokyo University and Olympus Optical Co. Ltd for primer design software using a novel algorism, and Nozomi Tsujino for preparation of this manuscript. Akiko Komi-Kuramochi was supported, in part, by a grant-in-aid from the Ministry of Education, Culture, Sports, Science and Technology, Japan (MEXT). This study was funded, in part, by an AIST research grant and a grant-in-aid from MEXT. There is no 
conflict of interest that would prejudice the impartiality of this study.

\section{References}

Bai XY, Miao D, Goltzman D \& Karaplis AC 2003 The autosomal dominant hypophosphatemic rickets R176Q mutation in fibroblast growth factor 23 resists proteolytic cleavage and enhances in vivo biological potency. Journal of Biological Chemistry 278 9843-9849.

Beyer TA, Werner S, Dickson C \& Grose R 2003 Fibroblast growth factor 22 and its potential role during skin development and repair. Experimental Cell Research 287 228-236.

Bikfalvi A, Klein S, Pintucci G \& Rifkin DB 1997 Biological roles of fibroblast growth factor-2. Endocrinology Review 18 26-45.

Bowe AE, Finnegan R, Jan de Beur SM, Cho J, Levine MA, Kumar R \& Schiavi SC 2001 FGF-23 inhibits renal tubular phosphate transport and is a PHEX substrate. Biochemical and Biophysical Research Communications 284 977-981.

Brauchle M, Fassler R \& Werner S 1995 Suppression of keratinocyte growth factor expression by glucocorticoids in vitro and during wound healing. Journal of Investigative Dermatology 105 579-584.

Brown RL, Ormsby I, Doetschman TC \& Greenhalgh DG 1995 Wound healing in the transforming growth factor-1 deficient mouse. Wound Repair and Regeneration 3 25-36.

Danilenko DM, Ring BD, Yanagihara D, Benson W, Wiemann B, Starnes CO \& Pierce GF 1995 Keratinocyte growth factor is an important endogenous mediator of hair follicle growth, development, and differentiation. American Journal of Pathology 147 145-154.

DuCros DL, Isaacs K \& Moore GP 1993 Distribution of acidic and basic fibroblast growth factors in ovine skin during follicle morphogenesis. Journal of Cell Science 105 667-674.

Gao Z, Flaitz CM \& Mackenzie IC 1996 Expression of keratinocyte growth factor in periapical lesions. Journal of Dentistry Research $\mathbf{7 5}$ 1658-1663.

Guo L, Degenstein L \& Fuchs E 1996 Keratinocyte growth factor is required for hair development but not for wound healing. Genes and Development 10 165-175.

Hebert JM, Rosenquist T, Gotz J \& Martin GR 1994 FGF5 as a regulator of the hair growth cycle: evidence from targeted and spontaneous mutations. Cell 78 1017-1025.

Igarashi M, Finch PW \& Aaronson SA 1998 Characterization of recombinant human fibroblast growth factor (FGF)-10 reveals functional similarities with keratinocyte growth factor (FGF-7). Journal of Biological Chemistry 273 13230-13235.

Itoh N \& Ornitz DM 2004 Evolution of the Fgf and Fgfr gene families. Trends in Genetics 20 563-569.

Jameson J, Ugarte K, Chen N, Yachi P, Fuchs E, Boismenu R \& Havran WL 2002 A role for skin $\gamma \delta$ T cells in wound repair. Science 296 747-749.

Jaye M, Schlessinger J \& Dionne CA 1992 Fibroblast growth factor receptor tyrosine kinases: molecular analysis and signal transduction. Biochimica et Biophysica Acta 1135 185-199.

Kawano M, Suzuki S, Suzuki M, Oki J \& Imamura T 2004 Bulgeand basal layer-specific expression of fibroblast growth factor 13 (FHF-2) in mouse skin. Journal of Investigative Dermatology 122 1084-1090.

Kawano M, Kuramochi-Komi A, Asada M, Suzuki M, Oki J, Jiang J \& Imamura T 2005 Comprehensive analysis of FGF and FGFR expression in skin: FGF18 is highly expressed in hair follicles and capable of inducing anagen from telogen stage hair follicles. Journal of Investigative Dermatology 124 877-885.

Marchese C, Chedid M, Dirsch OR, Csaky KG, Santanelli F, Latini C, LaRochelle WJ, Torrisi MR \& Aaronson SA 1995 Modulation of keratinocyte growth factor and its receptor in re-epithelializing human skin. Journal of Experimental Medicine 182 1369-1376.

Martin P 1997 Wound healing - aiming for perfect skin regeneration. Science 276 75-81.
Martin P, Hopkinson-Woolley J \& McCluskey J 1992 Growth factors and cutaneous wound repair. Progress in Growth Factor Research 4 $25-44$.

Mitsui S, Ohuchi A, Hotta M, Tsuboi R \& Ogawa H 1997 Genes for a range of growth factors and cyclin-dependent kinase inhibitors are expressed by isolated human hair follicles. British Journal of Dermatology 137 693-698.

Nakajima A, Shimizu S, Moriya H \& Yamazaki M 2003 Expression of fibroblast growth factor receptor-3 (FGFR3), signal transducer and activator of transcription-1, and cyclin-dependent kinase inhibitor p21 during endochondral ossification: differential role of FGFR 3 in skeletal development and fracture repair. Endocrinology 144 4659-4668.

Nakatake Y, Hoshikawa M, Asaki T, Kassai Y \& Itoh N 2001 Identification of a novel fibroblast growth factor, FGF-22, preferentially expressed in the inner root sheath of the hair follicle. Biochimica et Biophysica Acta 1517 460-463.

Ohuchi H, Hori Y, Yamasaki M, Harada H, Sekine K, Kato S \& Itoh N 2000 FGF10 acts as a major ligand for FGF receptor 2 IIIb in mouse multi-organ development. Biochemical and Biophysical Research Communications 277 643-649.

Ortega S, Ittmann M, Tsang SH, Ehrlich M \& Basilico C 1998 Neuronal defects and delayed wound healing in mice lacking fibroblast growth factor-2. PNAS 95 5672-5677.

Paddock HN, Schultz GS \& Mast BA 2003 Methods in re-epithelialization. A porcine model of partial-thickness wounds. Methods in Molecular Medicine 78 17-36.

Powers CJ, McLeskey SW \& Wellstein A 2000 Fibroblast growth factors, their receptors and signaling. Endocrine-Related Cancer 7 165-197.

Poss KD, Shen J, Nechiporuk A, McMahon G, Thisse B, Thisse C \& Keating MT 2000 Roles for Fgf signaling during zebrafish fin regeneration. Developmental Biology 222 347-358.

Reed MJ, Corsa A, Penn P, Pendergrass W, Saage EH \& Abrass IB 1998 Neovascularization of sponge implants in aged mice: delayed angiogenesis is coincident with decreased levels of TGF- $\beta 1$ and type I collagen. American Journal of Pathology 152 113-123.

Reed MJ, Koike T \& Puolakkainen P 2003 Wound repair in aging: a review. Methods in Molecular Medicine 78 217-237.

Rivard A, Fabre J, Silver M, Chen D, Murohata T, Kearney M, Magner M, Asahara T \& Isner J 1999 Age-dependent impairment of angiogenesis. Circulation 99 111-120.

Roberts AB \& Sporn MB 2001 Transforming growth factor- $\beta$. In The Molecular and Cellular Biology of Wound Repair, 2nd edn, pp. 275-308. Ed RAF Clark. New York: Plenum Press.

Rosenquist TA \& Martin GR 1996 Fibroblast growth factor signalling in the hair growth cycle: expression of the fibroblast growth factor receptor and ligand genes in the murine hair follicle. Developmental Dynamics 205 379-386.

Shah M, Revis D, Herrick S, Baillie R, Thorgeirson S, Ferguson M \& Roberts A 1999 Role of elevated plasma transforming growth factor-beta 1 levels in wound healing. American Journal of Pathology 154 1115-1124.

Singer AJ \& Clark RA 1999 Mechanism of disease: cutaneous wound healing. New England Journal of Medicine 341 738-746.

Steiling H \& Werner S 2003 Fibroblast growth factors: key players in epithelial morphogenesis, repair and cytoprotection. Current Opinion in Biotechnology 14 533-537.

Suzuki S, Kato T, Takimoto H, Masui S, Oshima H, Ozawa K, Suzuki S \& Imamura T 1998 Localization of rat FGF-5 protein in skin macrophage-like cells and FGF-5S protein in hair follicle: possible involvement of two Fgf-5 gene products in hair growth cycle regulation. Journal of Investigative Dermatology 111 963-972.

Werner S, Smola H, Liao X, Longaker MT, Krieg T, Hofschneider PH \& Williams LT 1994 The function of KGF in epithelial morphogenesis and wound re-epithelialisation. Science 266 819-822.

Yoshida S, Yamaguchi Y, Itami S, Yoshikawa K, Tabata Y, Matsumoto K \& Nakamura T 2003 Neutralization of hepatocyte 
growth factor leads to retarded cutaneous wound healing associated with decreased neovascularization and granulation tissue formation. Journal of Investigative Dermatology 120 335-343.
Received in final form 9 May 2005

Accepted 10 June 2005 